\title{
COMPRESSIVE STRENGTH CHARACTERISTICS OF CONCRETE MODIFIED WITH TREATED HIGH-DENSITY POLYETHYLENE
}

\author{
Iorwuese Anum ${ }^{1 *}$, Olorunmeye Fredrick Job ${ }^{2}$ \\ ${ }^{1}$ Department of Building, Modibbo Adama University, Yola, P.M.B. 2076, 640001 Adamawa State, \\ Nigeria \\ ${ }^{2}$ Department of Building, University of Jos, P.M.B. 2084, 930001 Plateau State, Nigeria
}

(Received: March 2021 / Revised: March 2021 / Accepted: May 2021)

\begin{abstract}
Waste plastic materials are typical wastes of interest to researchers and are arguably the most common forms of waste, especially in African cities. The reuse of plastic waste in concrete matrices has the potentials to contribute to the development of sustainable concrete likely to conserve resources and prevent pollution. However, the inclusion of plastics in concrete has been reported to have a negative impact on its compressive strength behaviour. This research is aimed at ameliorating this negative impact through pulverisation and chemical treatment of High-Density Polyethylene (HDPE) before its use as an admixture for concrete production. Concretes of Grades M25 and M50 were prepared using (150 x150 x 150) mm steel moulds, adopting the BRE mix design method. The concrete mix was modified with pulverised HighDensity Polyethylene (HDPE) treated with $20 \%$ hydrogen peroxide at $(0,0.25,0.5,0.75$, and $1 \%$ ) by weight of cement. Hydroplast-500, a superplasticizer was used throughout the study in order of 1000 litres $/ 50 \mathrm{~kg}$ by weight of cement. A constant water/cement ratio of 0.4 and 0.36 was adopted for requisite workability for Grades M25 and M50 concretes respectively. After 7, 28, and 90 days of curing in water, the concrete cubes were dried and tested for their compressive strengths. Results obtained showed that at HDPE content beyond $0.5 \%$, restrained hydration takes negative effects on the concrete. It was also shown that the designed compressive strengths of the tested samples were satisfactorily met in all cases indicating improvement in the compressive behaviour of the samples. Based on the findings of this study, it was recommended that treated pulverised HDPE could be used as an admixture in concretes without compromising their compressive strengths.
\end{abstract}

Keywords: Chemical Treatment; Compressive Strength; High-Density Polyethylene; Modified Concrete; Pulverisation.

\section{INTRODUCTION}

It is universally acknowledged that concrete is the most widely and conventionally used construction material worldwide as a result of its versatility, strength, durability, ease of use, and contribution to social progress, economic growth, and environmental protection (Paul, 2016; The Guardian, 2019). The extensive usage of concrete in construction according to Lafarge Holcim (2019) justifies why this conventional material is being continuously modified and developed to perform better in many situations.

*Corresponding author's email: ioranum@gmail.com, ianum@mautech.edu.ng Tel.+234-8036094154

DOI: https://doi.org/10.32783/csid-jid.v4i1.201 
According to Rutkowska et al. (2020), concrete has proven to be excellent disposal means for fly ash, silica fume, ground granulated blast furnace slag, and marble powder which can trap hazardous materials and also enhance the properties of concrete. Interestingly, the global construction industry consumes an estimated 20 billion tons of concrete every year and this large annual production of concrete consequently leads to an equally large estimated consumption of component materials of about 15 billion tons of aggregates and 4.2 billion tons of cement (Tosic et al., 2017). Taking into account the huge volume of concrete produced annually, the concrete industry is unquestionably one of the ideal mediums for the economic and safe use of millions of post-consumer waste plastics (Sandanayake et al., 2020).

Currently, global plastic production exceeded 311 million metric tons from 2.5 billion metric tons of solid waste generated in 192 countries (Bokani, 2019). A separate study by Statista (2021) revealed an estimated global plastic production of 368 million metric tons per year. In Nigeria for instance, the per capita consumption of plastics has grown by about $5 \%$ annually over the past ten years, from $4.0 \mathrm{~kg}$ in 2007 to $6.5 \mathrm{~kg}$ in 2017 , and is estimated to be $7.5 \mathrm{~kg}$ in 2020 (Bokani, 2019). This fast growth is attributed to the boost in industrialization and the rapid improvement in standards of living (Babafemi et al., 2018). Averill and Eldredge (2016) further adduced reasons for the phenomenal increase in the usage of plastics to its low density, strength, user-friendly designs, fabrication capabilities, lightweight, long life, and low cost. Therefore, plastic materials are typical waste materials of interest and are arguably the most common forms of waste in African cities (Smallstarter, n.d.).

Polyethylene according to Statista (2021) is the world's biggest and most popular tonnage plastic prepared by the catalytic polymerization of ethylene. High-Density Polyethylene (HDPE) which is defined by the density of greater or equal to $0.941 \mathrm{~g} / \mathrm{cm}^{3}$ accounts for $46 \%$ of total polyethylene production globally (Plasticsinsight.com, n.d.). High-Density Polyethylene possesses special properties such as increased resistance to permeability, good chemical resistance, high rigidity, high toughness and flexibility, improved heat resistance, good impact resistance, and lightweight which makes it a material of choice for many engineering applications (Dorigato et al., 2012; Plasticsinsight.com, n.d.).

Pulverised HDPE may be defined as plastics of HDPE parent materials that have been reclaimed, sorted, and reduced to smaller particles by grinding to create a new material with smaller particle sizes and improved surface area (Plasticsinsight.com, n.d.). Therefore, pulverised high-density polyethylene concrete is a composite material consisting of a cementbased matrix with ordered or randomly distributed particles of high-density polyethylene material as admixtures.

The compressive strength of concrete generally is its ability to resist compressive forces which is a force tending to compress or squeeze it together. The compressive strength of concrete is one of the most considered quantitative parameters because of its requirement when designing structural concrete elements (Slaiai, 2017).

A study by Naik, et al. (1996) has investigated the effects of post-consumer plastics in concrete and found that the inclusion of plastic fibers in concrete increases its ductility while improving fracture resistance, though with a negative impact on compressive strength and creep behaviour. This phenomenon according to the authors is because ordinary Portland cement concrete reinforced with plastics is liable to poor bonding due to the lack of chemical bond that exists between the materials. Studies by Lu et al. (1998) and Ebnesajjad (2011) have suggested that poor bonding between concrete and plastic materials may be improved by physical processing or chemical treatment of plastics prior to mixing. These techniques, according to these studies, have a good promise of improved bonding of plastics to cementitious materials as a result of bonding likely to develop with the surrounding matrix, which may result in higher strength. In 
light of all these arguments, this research is premised on ameliorating the negative impact of poor bonding between plastic based materials and concrete by pulverisation and chemical treating of High-Density Polyethylene (HDPE) before its use as an admixture for concrete production.

\section{LITERATURE REVIEW}

The compressive strength of concrete generally is its ability to resist compressive forces which is a force tending to compress or squeeze it together. The compressive strength of concrete is one of the most considered quantitative parameters because of its requirement when designing structural concrete elements (Slaiai, 2017). The compressive strength of plastic concretes depend on many parameters such as the water/cement ratio, constitution level of the plastic materials (mostly aggregates), and the type and shape of the waste plastic (Akçaözoğlu et al., 2010; Albano et al., 2009; Asokan et al., 2009; Babafemi et al., 2018). The mechanical properties of concrete containing recycled PET were identified by Cordoba et al. (2013) to depend on the particle size with the highest compressive strength obtained with the smallest sizes of PET $(0.5 \mathrm{~mm})$. The study also established the fact that mechanical properties of plastic concrete such as compressive strength increases with a reduced particle size of plastics and with lower concentrations of the plastic content. The lower sizes and concentrations of plastic particles create fewer spaces in the concrete, and in consequence, strength is increased (Ávila Córdoba et al., 2013). The compressive strength of plastic shreds in concrete was studied by Naik, et al. (1996). The study reported a compressive strength decrease with an increase in the amount of plastic in concrete, particularly above $0.5 \%$ plastic addition.

Patil et al. (2014) reported that the modified concrete mix, with the addition of plastic aggregate replacing conventional aggregate up to a certain $20 \%$ gives strength within the permissible limit but decreased compressive strength when plastic was replaced with coarse aggregate. Besides, Raghatate and Polytechnic (2012) reported that there is about a 20\% reduction in compressive strength at 28 days of curing using the plastic pieces in concrete. In each case reported, compressive strength reduction was a result of improper bonding between organic plastic materials and inorganic cementitious materials.

$\mathrm{Gu}$ and Ozbakkaloglu (2016), attributed the reduction in compressive strength to one or a combination of the following: the elastic modulus of the plastic aggregates/filler aggregates being lower than the natural concrete aggregate, the low bond strength between the surface of the plastic aggregate/filler and the cement paste, the restrained cement hydration reaction near the surface of the plastic resulting from the hydrophilic nature of the plastics or the high air content and porosity of the plastic concrete. The use of recycled plastic fibers with a high ultimate tensile strength and smaller fiber content results in a more significant improvement in compressive strength than fibers with low compressive strength. Also, straight fibers increased compressive strength more than those with embossed geometry (Fraternali et al., 2014). Additionally, the compressive strength of plastic concrete was increased with the injection of plasticiser (Rai et al., 2012).

It can be seen that the compressive strength of plastic concrete is likely to be increased substantially without compromising its performance if plastic particles are further processed or treated to improve the bonding of the composites in a superplasticised environment. The pulverization of the polyethylene into a powder is presumed to reduce their particle sizes, hence expected to increase the compressive strength. The limitations of most previous research attempts on the use of plastics in concrete were the fact that plastic used presented wider surface areas (which likely inhibited hydration of cement) or was not treated (which may have affected the bonding to cementing materials). 


\section{METHODS}

\subsection{Materials}

The materials used in this research are: 'BUA' (42.5R grade) brand of Ordinary Portland Cement conforming to ASTM C 150 (2015). Pulverised High-Density Polyethylene was sourced from landfills in Jimeta, Yola North Local Government Area of Adamawa State, Nigeria. The High-Density Polyethylene (HDPE) were first sorted, cleaned, washed, and mechanically pulverised into smaller particles passing a $2 \mathrm{~mm}$ British Standard (BS) sieve and chemically treated with $20 \%$ hydrogen peroxide to make the particles hydrophilic. Sieve analysis was then performed on the pulverised High-Density Polyethylene after taking the samples to approximately Saturated Surface Dry (SSD) condition as shown in Figure 1.

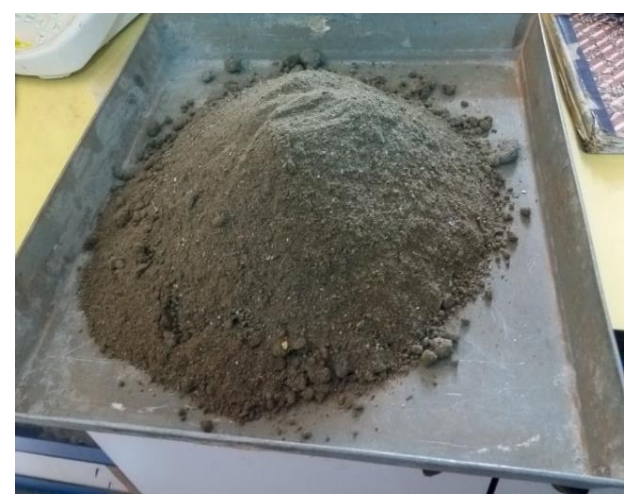

Figure 1 Pulverised and Sieved High-Density Polyethylene

Hydroplast - 500 conforming to ASTM C 494 (2015) was procured at Armosil West Africa Garki, Abuja, and used as a superplasticiser. Good quality Zone I river sand passing through 4.75mm BS sieve sourced from Jere town in Kagarko Local Government Area of Kaduna State was used.

Table 1 Properties of Materials Used

\begin{tabular}{|c|c|c|c|c|c|}
\hline Properties & Cement & HDPE & $\begin{array}{c}\text { Fine } \\
\text { Aggregate }\end{array}$ & $\begin{array}{c}\text { Coarse } \\
\text { Aggregate }\end{array}$ & $\begin{array}{l}\text { Hydroplast- } \\
500\end{array}$ \\
\hline Specific Gravity & 3.15 & 1.03 & 2.66 & 2.62 & 1.175 \\
\hline Standard Consistency & $30 \%$ & - & - & - & - \\
\hline Initial Setting Time (min) & 60 & - & - & - & - \\
\hline Final Setting Time (min) & 320 & - & - & - & - \\
\hline Bulk Density $\left(\mathrm{Kg} / \mathbf{m}^{3}\right)$ & 1440 & - & - & - & - \\
\hline $\begin{array}{l}\text { Compressive Strength at } 3 \\
\text { Days }\left(\mathrm{N} / \mathbf{m m}^{2}\right)\end{array}$ & 11.3 & - & - & - & - \\
\hline $\begin{array}{l}\text { Compressive Strength at } 7 \\
\text { Days }\left(\mathbf{N} / \mathbf{m m}^{2}\right)\end{array}$ & 25 & - & - & - & - \\
\hline $\begin{array}{l}\text { Compressive Strength at } 28 \\
\text { Days }\left(\mathrm{N} / \mathrm{mm}^{2}\right)\end{array}$ & 46 & - & - & - & - \\
\hline Moisture Content (\%) & - & 0.55 & 0.13 & 0.2 & - \\
\hline Water Absorption (\%) & - & 0.067 & 0.38 & 0.29 & - \\
\hline Appearance & Grey & $\begin{array}{l}\text { Ash- } \\
\text { grey }\end{array}$ & - & - & Dark brown \\
\hline
\end{tabular}

The suitability of the sand for the intended use was ascertained in the laboratory in accordance with the provisions of BS EN 12620 (2013). 20mm nominal sizes natural machined crushed rock sourced at Dutse Alhaji, Abuja and potable water obtained from Nigerian Building and Road Research institute laboratory, supplied by the Federal Capital Territory Water Board was used. This water was used throughout this research work both for mixing as well as curing of 
the concrete and in accordance with the provisions of ASTM C1602/C1602M (2012). The properties of the materials are presented in Table 1.

\subsection{Methods}

The high-density polyethylene was collected, sorted, cleaned, washed, and pulverised into smaller particles using a locally fabricated pulverizing machine. The High-Density Polyethylene powder was then subjected to pretreatment by immersing it in a $20 \%$ solution of hydrogen peroxide for 20 minutes and then sun-dried to saturated surface dry condition. Figure 2(a) and 2(b) shows the Scanning Electron Microscopy (SEM) images of the treated and untreated Pulverised HDPE. The concrete specimens were prepared at the Materials and Concrete Laboratory, Nigerian Building and Road Research Institute (NIBRRI) headquarters Abuja, Nigeria using $(150 \times 150 \times 150) \mathrm{mm}$ steel moulds. The cubes were prepared in accordance with the provisions of BS EN 12390-3 (2002). Concrete mixes were prepared using the BRE method of mix design. Table 2 shows the number of materials required per cubic meter of concrete as computed by the mix design. The investigation was carried out on Grade 25 and Grade 50 concretes representing medium-strength concretes (Grade 25) and high strengths (Grade 50) concretes respectively.

The samples were prepared with the pulverised and treated HDPE of fine consistency, precisely those passing through $2.00 \mathrm{~mm}$ BS sieve, and added in percentages of $(0,0.25,0.5,0.75$, and 1$)$ by weight of cement. Dosages of hydroplast-500 in order of 10001 itres/ 50kg by weight of cement was used throughout the study as recommended by the manufacturers to enhance the workability of the matrix.

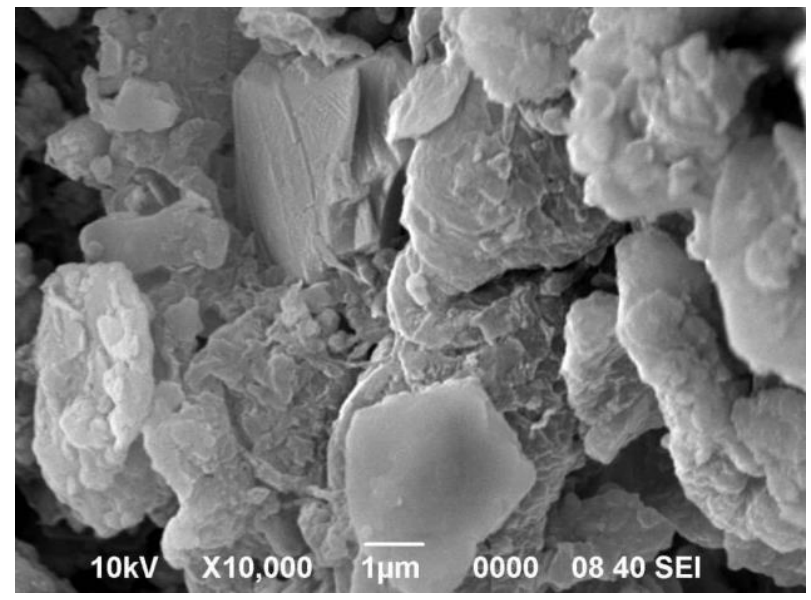

Figure 2(a) SEM image of Untreated Pulverised HDPE (X10, 000 Magnification)

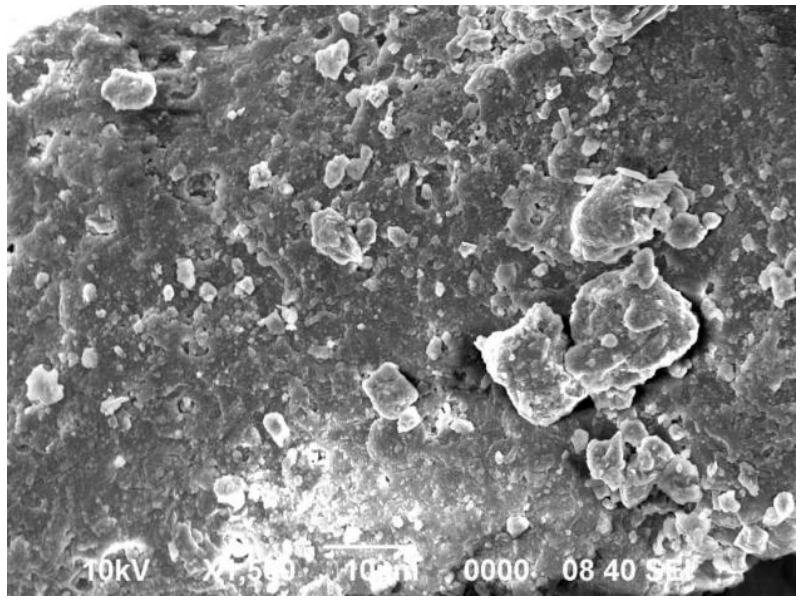

Figure 2(b) SEM Image of Treated Pulverised $\operatorname{HDPE}(\mathrm{X} 1,500$ Magnification)

A constant water/cement ratio of 0.4 and 0.36 for requisite workability was adopted for Grades 25 and Grades 50 concretes respectively after trial mixes.

The fresh concrete was cast into the appropriate moulds (Figure 3) and vibrated for at least 25 seconds in accordance with ASTM C 192/ C192M (2016) using an electrically operated small size poker vibrator. After 24 hours of casting, the concrete beams were demoulded, weighed, and completely cured in water tanks. The compressive strength tests were carried out on the $150 \times 150 \times 150 \mathrm{~mm}$ hardened concrete cubes after curing for 7, 28, and 90 days and in accordance with BS EN 12390-3 (2002) using a universal testing machine as shown in Figure 4. 
Table 2 Quantity of Ingredients Required (kg) Per Cubic Metre of Concrete

\begin{tabular}{|c|c|c|}
\hline \multirow[b]{2}{*}{ Ingredient (Kg) } & \multicolumn{2}{|c|}{ Concrete Grades } \\
\hline & $\mathrm{C} 25$ & C50 \\
\hline Cement & 360 & 430 \\
\hline Fine Aggregate & 630 & 570 \\
\hline Coarse Aggregate & 1330 & 1330 \\
\hline Water & 145 & 155 \\
\hline Hydroplast-500 & 7.2 & 8.6 \\
\hline \multicolumn{3}{|l|}{ Pulverized HDPE } \\
\hline $0.0 \%$ & 0 & 0 \\
\hline $0.25 \%$ & 0.90 & 1.08 \\
\hline $0.50 \%$ & 1.80 & 2.15 \\
\hline $0.75 \%$ & 2.70 & 3.25 \\
\hline $1.0 \%$ & 3.60 & 4.30 \\
\hline
\end{tabular}

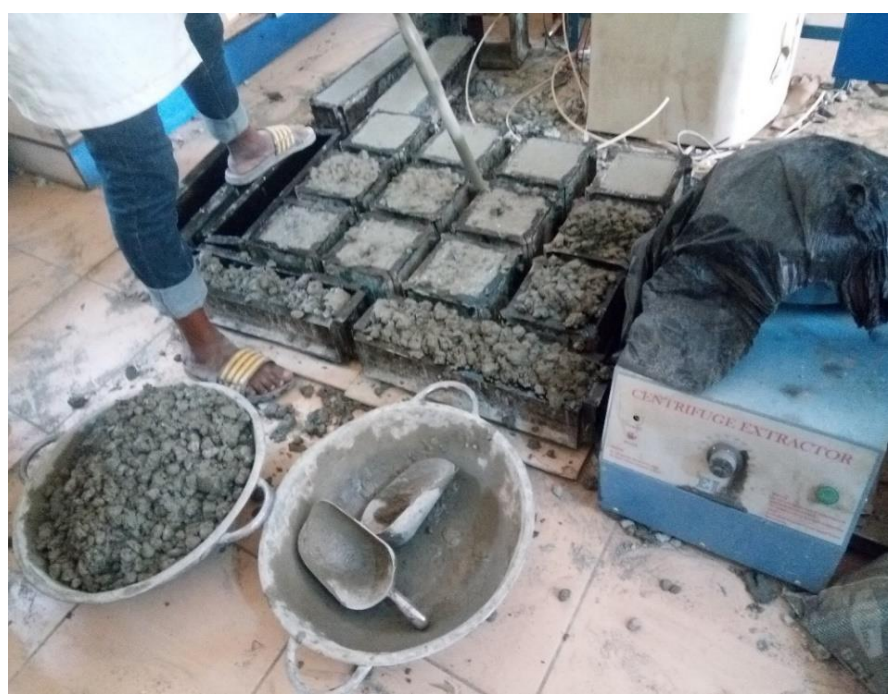

Figure 3 Concrete Cubes Cast with (150 X 150) mm Steel Moulds

The average failure loads were used in obtaining the compressive strength, using the relationship in equation (2).

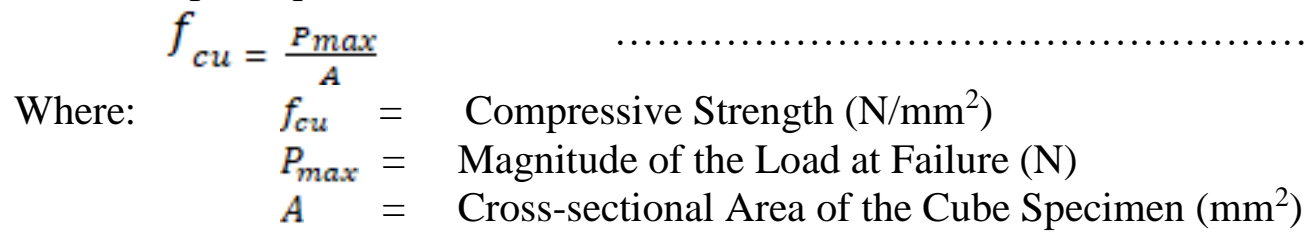




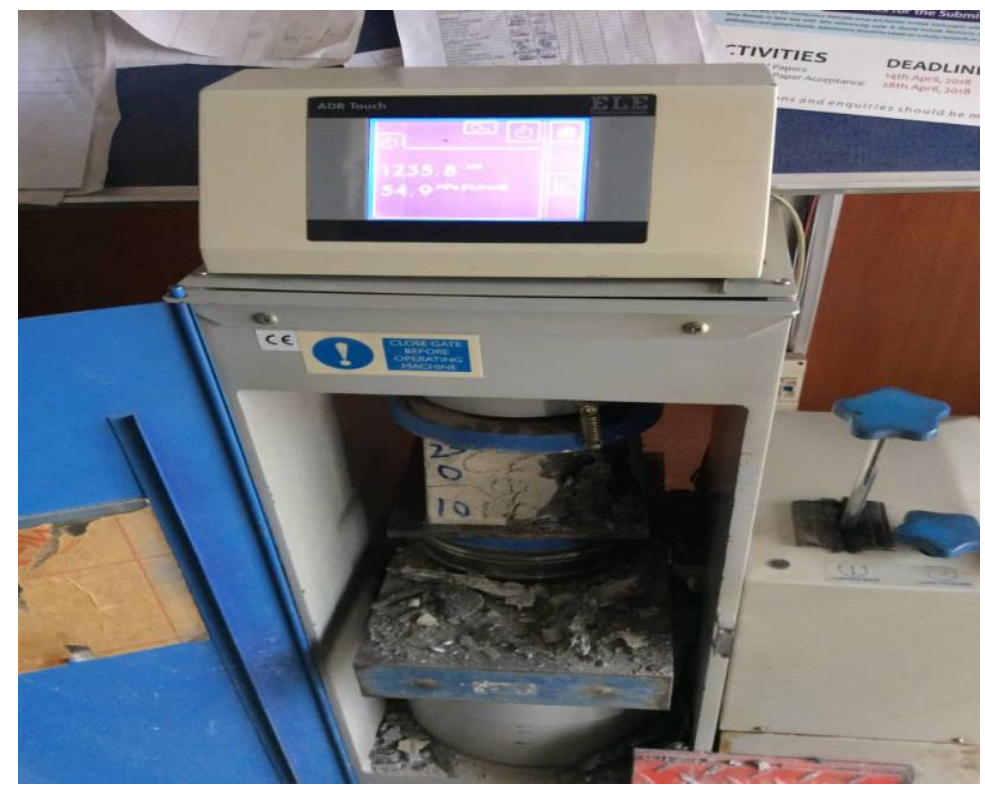

Figure 4 Determination of Compressive Strength of Cubes Using Universal Testing Machine

\section{RESULTS AND DISCUSSION}

Figures 5 (a) and 5(b) show the relationship between compressive strength development and hydration periods of 7, 28, and 90 days for grades M25 and M50 concrete respectively. A critical analysis further revealed that the compressive strength of all concrete specimens increased with curing age compared on the basis of 90 days indicating that no noticeable degradation of the concrete occurred within the 90 days test. Compressive strength however decreased with the inclusion of pulverised HDPE with the least reduction of $19.09 \%$ $\left(29.67 \mathrm{~N} / \mathrm{mm}^{2}\right)$ for Grade M25 while $16.04 \%\left(45.32 \mathrm{~N} / \mathrm{mm}^{2}\right)$ was recorded as the least reduction for Grade M50 concretes in all cases at $0.5 \%$ HDPE by weight of cement. This implies that 0.5 $\%$ HDPE content is the optimum content beyond which restrained hydration takes negative effects on the concrete. The reduction in compressive strength could be attributed to the restrained cement hydration reaction near the surface of the HDPE resulting from their hydrophilic nature.

The compressive strength of the control mixes was observed to be higher than that of all mixes containing pulverised HDPE. However, a minimum strength of $14.35 \mathrm{~N} / \mathrm{mm}^{2}$ and $25.05 \mathrm{~N} / \mathrm{mm}^{2}$ was obtained for Grade M25 concretes at 7 and 28 days of curing while a minimum of $33 \mathrm{~N} / \mathrm{mm}^{2}$ and $50 \mathrm{~N} / \mathrm{mm}^{2}$ was obtained for Grade M50 concretes at 7 and 28 days of curing respectively. These values correspond to the minimum expected designed strength of $65 \%$ at 7 days of curing and $99 \%$ strength at 28 days of curing in water suggesting that the designed strength was satisfactorily met in all cases. This finding is considered as an improvement over the previous findings (Atul \& Polytechnic, 2012; Gu \& Ozbakkaloglu, 2016; Naik et al., 1996), who observed the same trend of strength reduction of the modified concrete with plastic materials. The improved performance in this study could be probably attributed to the reduction in the particle sizes of the HDPE via pulverisation as well as increased coverage of the polymer surface with $\mathrm{R}-\mathrm{OH}$ and $\mathrm{R}-\mathrm{COOH}$ sites produced by the oxidizing hydrogen peroxide during treatment of the HDPE. The treatment is believed to have made the particles hydrophilic, hence allowing them to adhere better to cement. 


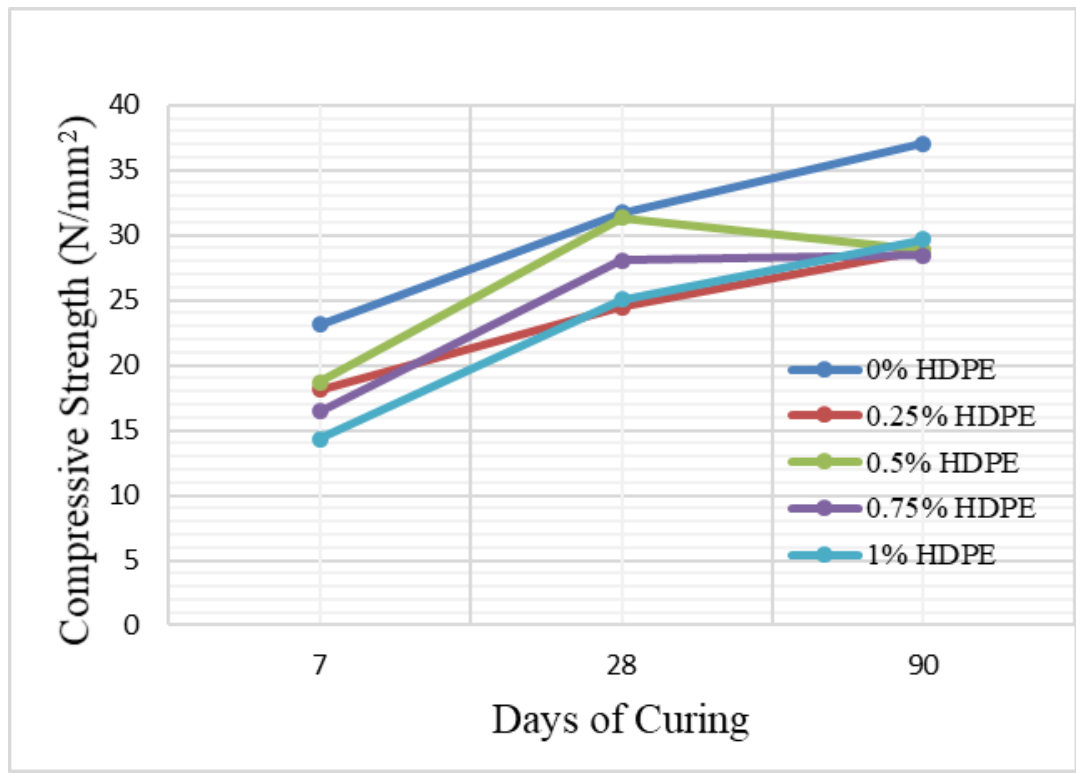

Figure 5(a) Compressive Strength with Curing Period for M 25 Concrete

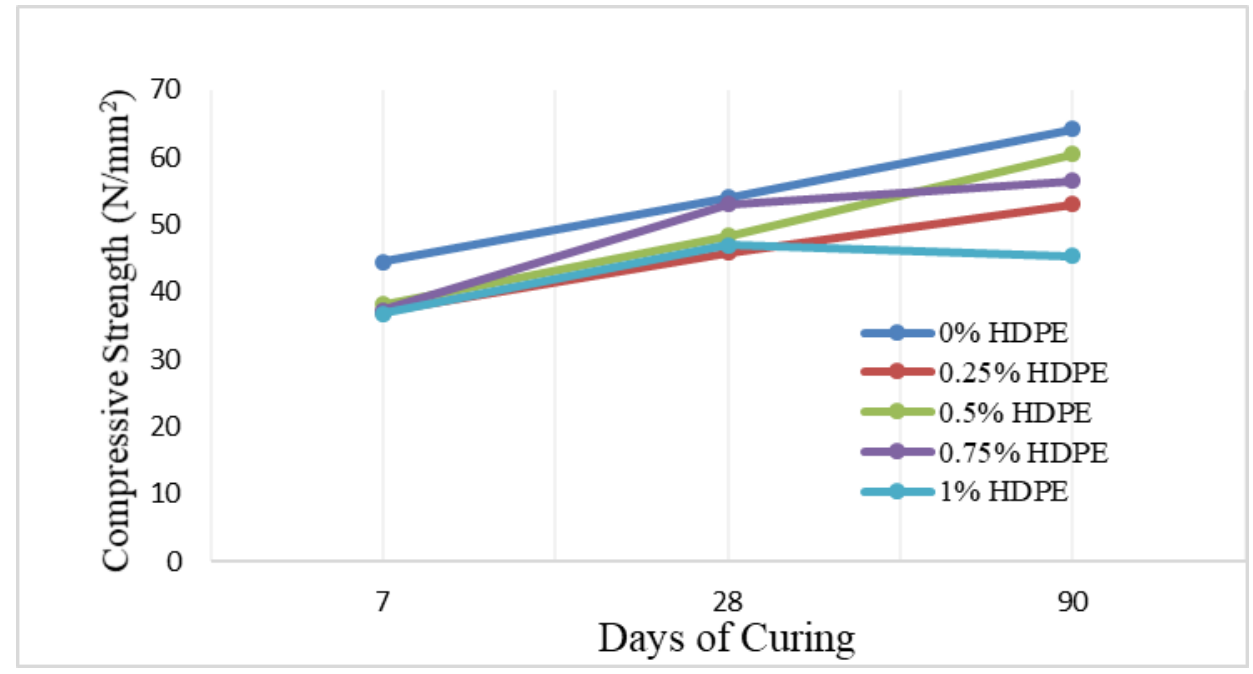

Figure 5(b) Compressive Strength with Curing Period for M50 Concrete

\section{CONCLUSION}

The following conclusions were drawn from the study of compressive strength characteristics of concrete modified with treated high-density polyethylene. The rough and reduced particle size with increased surface areas of the treated Pulverized High-Density Polyethylene as revealed by SEM substantially improved the bonding of plastic to cementitious materials as compared to the untreated samples.

Compressive strengths of all concrete specimens increased with curing age compared on the basis of 90 days tested but decreased with the inclusion of Pulversised High-Density Polyethylene with the least reduction of $19.09 \%\left(29.67 \mathrm{~N} / \mathrm{mm}^{2}\right)$ for Grade M25 while 16.04\% $\left(45.32 \mathrm{~N} / \mathrm{mm}^{2}\right)$ for Grade M50 concrete.

The study has shown the benefits of pulverisation and chemical treatment of HDPE on improving compressive strength properties of concrete, thus contributing to the body of knowledge on the use of waste plastic concrete. The study empirically revealed that the 
incorporation of $0.5 \%$ of HDPE by weight of cement gives the optimum strength improvement for both Grade M25 and M50 concretes. The study has thus provided a guild to practitioners on the use of High-Density Polyethylene in concrete for construction purposes. Based on the findings of this study, it was recommended that $0.5 \%$ by weight of cement of treated pulverised HDPE could be used as an admixture in normal and high strengths concretes without compromising their compressive strengths.

This study limited the treatment of High-Density Polyethylene with only hydrogen peroxide. Therefore, the research suggested future studies to look at the effects of using other oxidizing chemicals for the treatment of High-Density Polyethylene. Similarly, the effects of treatment on HDPE should also be investigated.

\section{REFERENCES}

Akçaözoğlu, S., Atiş, C. D., \& Akçaözoğlu, K. (2010). An investigation on the use of shredded waste PET bottles as aggregate in lightweight concrete. Waste Management, 30(2), 285-290. https://doi.org/10.1016/j.wasman.2009.09.033

Albano, C., Camacho, N., Hernández, M., Matheus, A., \& Gutiérrez, A. (2009). Influence of content and particle size of waste pet bottles on concrete behavior at different w/c ratios. Waste Management, 29(10). https://doi.org/10.1016/j.wasman.2009.05.007

Asokan, P., Osmani, M., \& Price, A. D. F. (2009). Assessing the recycling potential of glass fibre reinforced plastic waste in concrete and cement composites. Journal of Cleaner Production, 17(9). https://doi.org/10.1016/j.jclepro.2008.12.004

ASTM, C.-12. (2012). Standard Specification for Mixing Water Used in the Production of Hydraulic Cement Concrete. ASTM International, $i(\mathrm{c})$.

ASTM C192/C192M. (2016). Standard Practice for Making and Curing Concrete Test Specimens in the Laboratory. American Society for Testing and Materials.

ASTM C494. (2015). Standard Specification for Chemical Admixtures for Concrete. ASTM International, February.

ASTM Committee C01.29. (2015). ASTM C1012/C1012M -15: Standard Test Method for Length Change of Hydraulic-Cement Mortars Exposed to a Sulfate Solution. In Annual Book of ASTM Standards Volume 04.01.

Atul, R., \& Polytechnic, A. S. (2012). Use of Plastic in Concrete to improve its Properties. In International Journal of Advanced Engineering Research and Studies E-ISSN2249-8974 IJAERS.

Averill, B., \& Eldredge, P. (2016). General Chemistry: Principles, Patterns, and Applications 1.0 | Flat World Education. Flat World Education.

Ávila Córdoba, L., Martínez-Barrera, G., Barrera Díaz, C., Ureña Nuñez, F., \& Loza Yañez, A. (2013). Effects on mechanical properties of recycled PET in cement-based composites. International Journal of Polymer Science, 2013. https://doi.org/10.1155/2013/763276

Babafemi, A. J., Šavija, B., Paul, S. C., \& Anggraini, V. (2018). Engineering properties of concrete with waste recycled plastic: A review. In Sustainability (Switzerland) (Vol. 10, Issue 11). https://doi.org/10.3390/su10113875

Bokani, U. A. (2019). Current status of waste management and plastic management in Nigeria, Policy \& Industry Aspects. http://www.unido.or.jp/files/191007_UNIDOSeminar_Nigeria.pdf

British Standard Institution. (2002). BS EN 12390-3: Method of determination of compressive strength of concrete cubes.

British Standard Institution. (2013). BS EN 12620: Methods of sampling and testing of minerals aggregates, sands and fillers.

Dorigato, A., D’Amato, M., \& Pegoretti, A. (2012). Thermo-mechanical properties of high 
density polyethylene - Fumed silica nanocomposites: Effect of filler surface area and treatment. Journal of Polymer Research, 19(6). https://doi.org/10.1007/s10965-012-9889-2

Ebnesajjad, S. (2011). Surface preparation of thermoplastics, thermosets, and elastomers. In Handbook of Adhesives and Surface Preparation. https://doi.org/10.1016/B978-1-43774461-3.10007-0

Fraternali, F., Spadea, S., \& Berardi, V. P. (2014). Effects of recycled PET fibres on the mechanical properties and seawater curing of Portland cement-based concretes. Construction and Building Materials, 61, 293-302. https://doi.org/10.1016/j.conbuildmat.2014.03.019

Gu, L., \& Ozbakkaloglu, T. (2016). Use of recycled plastics in concrete: A critical review. In Waste Management (Vol. 51). https://doi.org/10.1016/j.wasman.2016.03.005

LafargeHolcim Ltd. (2019). Sustainability Performance Report 2019. https://www.lafargeholcim.com/sites/lafargeholcim.com/files/atoms/files/02272020sustainability-lafargeholcim_fy_2019_data_report-en-update2.pdf

Lu, W., Fu, X., \& Chung, D. D. L. (1998). A comparative study of the wettability of steel, carbon, and polyethylene fibersby water. Cement and Concrete Research, 28(6). https://doi.org/10.1016/S0008-8846(98)00056-8

Naik, T. R., Singh, S. S., Huber, C. O., \& Brodersen, B. S. (1996). Use of post-consumer waste plastics in cement-based composites. Cement and Concrete Research, 26(10). https://doi.org/10.1016/0008-8846(96)00135-4

Patil, P. S., Mali, J. R., Tapkire, G. V, \& Kumavat, H. R. (2014). Innovative techniques of waste plastic used in concrete mixture. International Journal of Research in Engineering and Technology, 3(9), 2321-7308. https://doi.org/10.5402/2012/469272

Paul, A. (2016). 10 Advantages of Concrete as Construction Material | Why Concrete . https://civildigital.com/10-advantages-concrete-construction-material-concrete/

Plasticsinsight.com. (n.d.). HDPE Production Capacity, Price and Market. Retrieved May 15, 2021, from https://www.plasticsinsight.com/resin-intelligence/resin-prices/hdpe/

Rai, B., Rushad, S. T., Kr, B., \& Duggal, S. K. (2012). Study of Waste Plastic Mix Concrete with Plasticizer. ISRN Civil Engineering, 2012, 1-5. https://doi.org/10.5402/2012/469272

Rutkowska, G., Wichowski, P., Franus, M., Mendryk, M., \& Fronczyk, J. (2020). Modification of ordinary concrete using fly ash from combustion of municipal sewage sludge. Materials, 13(2). https://doi.org/10.3390/ma13020487

Sandanayake, M., Bouras, Y., Haigh, R., \& Vrcelj, Z. (2020). Current sustainable trends of using waste materials in concrete-a decade review. In Sustainability (Switzerland) (Vol. 12, Issue 22). https://doi.org/10.3390/su12229622

Slaiai, K. (2017). Concrete Strength and Concrete Durability, Are they different concepts? https://www.linkedin.com/pulse/concrete-strength-durability-different-concepts-khaldoonslaiai

Smallstarter. (n.d.). From Waste to Wealth - How to build a profitable business out of Africa's huge waste market - Smallstarter Africa. Retrieved May 15, 2021, from https://www.smallstarter.com/browse-ideas/make-money-from-waste/

Statista. (2021). - Global plastic production 1950-2019 | Statista. https://www.statista.com/statistics/282732/global-production-of-plastics-since-1950/

The Guardian. (2019). Concrete: the most destructive material on Earth . https://www.theguardian.com/cities/2019/feb/25/concrete-the-most-destructive-material-onearth

Tosic, N., Marinkovic, S., \& Stojanovic, A. (2017). Sustainability of the concrete industry: Current trends and future outlook. Tehnika, 72(1). https://doi.org/10.5937/tehnika1701038t 